This is a postprint version of the following published document:

Pazos, M. \& Baselga, J. (2003). Limiting thickness estimation in polycarbonate lenses injection using CAE tools. Journal of Materials Processing Technology, 143-144, pp. 438-441..

DOI: $10.1016 / \mathrm{S} 0924-0136(03) 00425-4$

(C) Elsevier, 2003

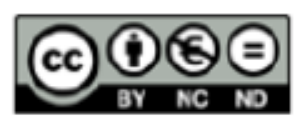

This work is licensed under a Creative Commons Attribution-NonCommercialNoDerivatives 4.0 International License. 


\title{
Limiting thickness estimation in polycarbonate lenses injection using CAE tools
}

\author{
Miguel Pazos*, Juan Baselga, Julio Bravo \\ Instituto de Tecnología Química y Materiales, Universidad Carlos III de Madrid, Avda. Universidad 30, 28911 Leganés, Spain
}

\begin{abstract}
Some commercial software packages that simulate injection processes are available. It is possible to design moulds and to optimise the processes by using computer-aided engineering (CAE) tools. In addition, we employ C-MOLD, one of the best commercial packages, to determine the limiting thickness in polycarbonate lenses manufactured by injection. In this work we use a simple geometry to study the variation of different magnitudes as a function of the lowest thickness in biconcave and biconvex lenses. The parameters studied are the variation of temperature, pressure and piece mass during the fillin time, air traps, melt lines and weld lines. The flo problem of the plastic in the mould is very different for biconcave and biconvex lenses. While the limiting thickness is in the centre for the biconcave lens, the perimeter is the limiting zone for the flo in the biconvex lens. For both geometries, however, the minimum thickness is limited by a mechanical and an aesthetic factor. If we take into account the variation of temperature, pressure and mass with minimum thickness, the mechanical limiting thickness can be estimated as $500 \mu \mathrm{m}$. But, if we also consider the evolution of the air traps and the melt and weld lines, which greatly influenc the aesthetic factor, the resulting limiting thickness is $650 \mu \mathrm{m}$ in the centre of biconcave lenses and $500 \mu \mathrm{m}$ in the peripheric area of biconvex lenses.
\end{abstract}

Keywords

C-MOLD; Injection moulding; CAE tools; Critical thickness

\section{Introduction}

The mould and part design of plastic parts for injec-tion moulding is a complicated process. Considerations for producing a part range from cost and speed of production to structural, ergonomics and aesthetic requirements. Some commercial software packages can simulate the process [1] and thus help us design the mould and optimise the process. Research on plastic injection moulding has included a growing number of scientifi works on optimisation algorithms to assist the designer [2-6]. Many other authors have used these computer-aided engineering (CAE) tools to optimise injection process variables like the minimum pressure [7], the reduction of distortion balancing the flo in the mould cavity [8], the fibr orientation in reinforced plastics $[9,10]$, the determination and interpretation of the weld/melt lines [11], and the shrinkage prediction [12]. In addition, when work done with CAE tools is compared with the rules based on the knowledge that has been acquired so far, it generally reinforces these. The software packages do not only simulate and optimise the injection processes, they can also test those rules that have been established by experts throughout decades of work.

In this work we use C-MOLD to estimate the critical thickness for injection by studying the flo parameters as a thickness function in biconcave and biconvex lenses [13]. This is a new method used by our research group to estimate critical conditions plotting different parameters versus the thickness $[14,15]$ and studying the evolution of air traps, melt and weld lines, etc.

\section{Computer modelling details}

The geometry of the lenses is modelled on concentrical rings. Its approximation to the real geometry of biconcave and biconvex lenses allows us to change the thickness very easily. Fig. 1 depicts this geometrical model. The geometrical model is composed of 10 rings with a diameter difference of $5 \mathrm{~mm}$ and a difference in thickness of $0.5 \mathrm{~mm}$ from one to the next. For the biconcave lenses the strongest restriction for the melt plastic $\mathrm{fl} \mathrm{w}$ is located in the centre. The models that were studied had thicknesses from 0.2 to $0.65 \mathrm{~mm}$. The limiting thickness for the biconvex lenses is in the edge and we considered thicknesses from 0.3 to $0.75 \mathrm{~mm}$.

* Corresponding author.

E-mail address: jbaselga@ing.uc3m.es (M. Pazos). 


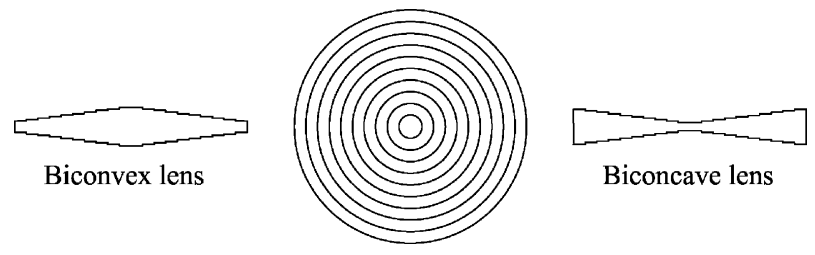

Fig. 1. Geometrical model for biconcave and biconvex lenses.

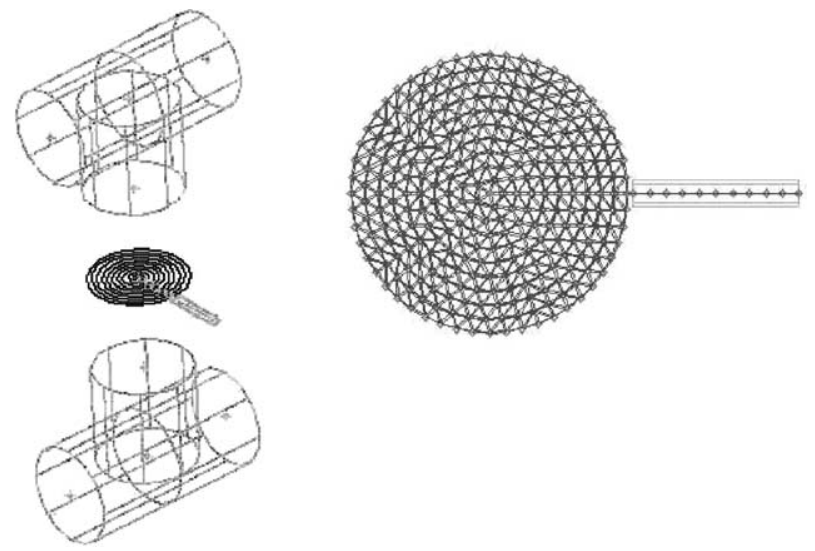

Fig. 2. Mesh geometry of the lenses (three-node elements) and of the cooling and runner channels (two-node elements).

The gate of the runner was located in the perimeter because of the optical requirements of the lens. Three-node triangular elements with $2.5 \mathrm{~mm}$ sides were used to generate the mesh of the lens area and two-node linear elements for the runner and cooling channels. Fig. 2 shows the lens geometry, the runner and the cooling channel (baffles as well as the mesh.

Two fillin times were used, $0.3 \mathrm{~s}$, which is the optimal time to obtain the simulations with the minimum injection pressure and $0.6 \mathrm{~s}$, which is in agreement with the fillin times used in industrial injection processes. The optimal fillin time was determined by searching the minimum injection pressure for the biconcave lens with $800 \mu \mathrm{m}$ of minimum thickness. The time range studied was from 0.01 to $1.2 \mathrm{~s}$, and the minimum of the curve was around $0.3 \mathrm{~s}$.

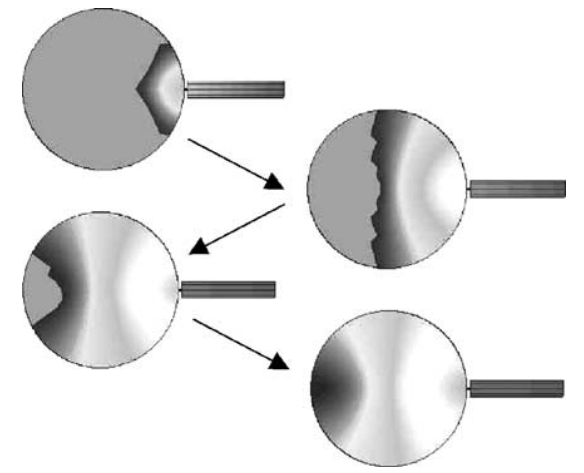

Fig. 4. Melt front advance for biconcave lenses with minimum thickness of $300 \mu \mathrm{m}$.

The material used was LEXAN OQ3820, a polycarbonate with optical quality supplied by General Electric Plastics.

Steel P-20 was chosen as the mould material and oil as the cooling fluid The Arburg 220E18 with a maximum injection pressure of $353 \mathrm{MPa}$ and a clamp force of 40,000 $t$ was used for the simulation.

\section{Results and discussion}

Several variables have been studied as a function of the thickness. In previous works $[13,14]$ the temperature and pressure differences were variables that were most sensitive to the thickness variation on the thinnest area of an ISO-MC card. The study has been extended to include the weight and clamp force differences and very similar results have been obtained.

\subsection{Biconcave lens}

Fig. 3 depicts the pressure differences between the elements with the maximum and minimum pressure at the end of the fillin processes, using times of 0.6 and $0.3 \mathrm{~s}$ for the biconcave lenses. In both plots the pressure differences increase rapidly if the thickness of the central part of the
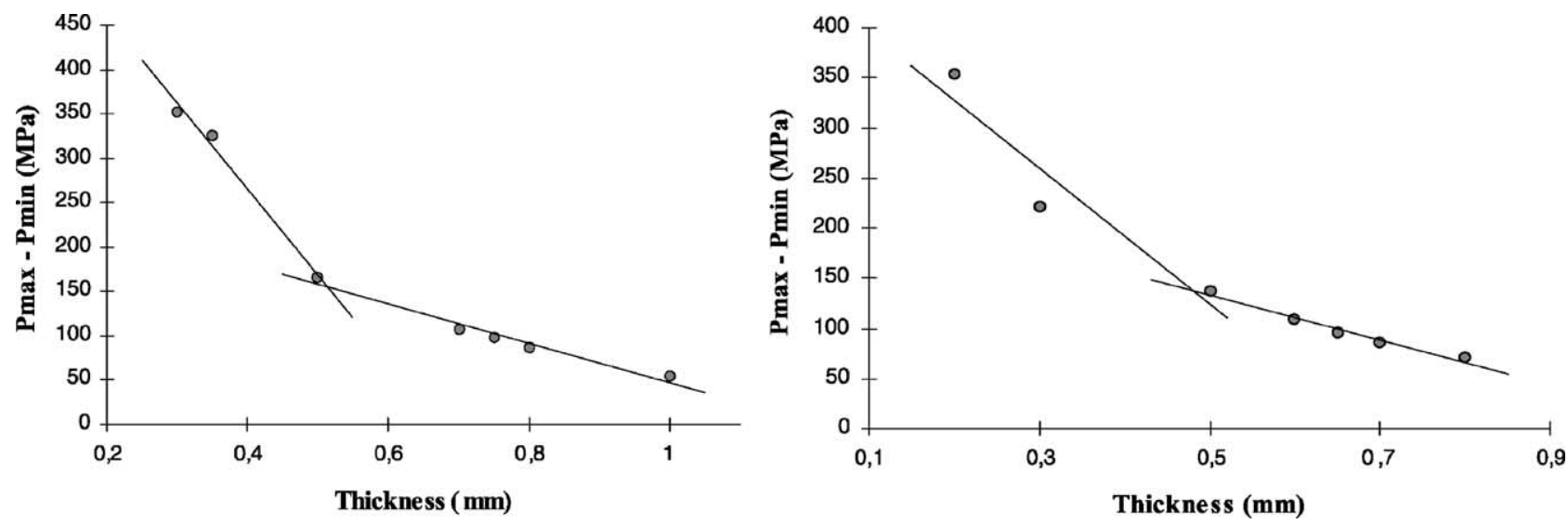

Fig. 3. Pressure differences between the elements with maximum and minimum pressure at the end of the fillin process using injection times of $0.6 \mathrm{~s}$ (left) and $0.3 \mathrm{~s}$ (right) as a function of the central lens thickness in biconcave lenses. 


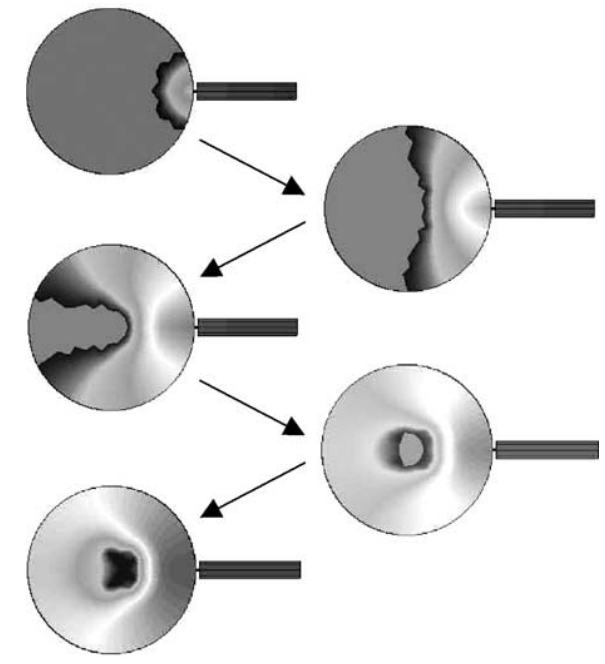

Fig. 5. Melt front advance for biconcave lenses with minimum thickness of $800 \mu \mathrm{m}$.

lenses is lower than $500 \mu \mathrm{m}$ and they increase more slowly with higher thicknesses. The representation of the weight and clamp force variation is very similar and the thickness where the behaviour changes is also $500 \mu \mathrm{m}$.

Figs. 4 and 5 show the melt-front advance for biconcave lenses with minimum thicknesses of 300 and $800 \mu \mathrm{m}$, re- spectively. The melt-front is almost fla for the lens with $800 \mu \mathrm{m}$ while it surrounds the central part of the lens if the thickness is $300 \mu \mathrm{m}$.

Fig. 6 depicts the evolution of the weld lines and the air traps for the different thicknesses using $0.3 \mathrm{~s}$ as the fillin time. While for 200 and $300 \mu \mathrm{m}$ there are air traps and weld lines in the central zone, for 500 and $600 \mu \mathrm{m}$ these only appear close to the edge and for $650 \mu \mathrm{m}$ weld lines do not appear at all and air traps hardly do either. This representation confirm the idea that with thicknesses higher than $500 \mu \mathrm{m}$ the quality of the piece is good and the process conditions are optimal but if the thickness is lower the process is not conducive to the most favourable results. If $0.6 \mathrm{~s}$ are fi ed as fillin time the results obtained for the air traps and weld lines are very similar.

\subsection{Biconvex lens}

The biconvex lens has only been studied with a fillin time of $0.6 \mathrm{~s}$ because we cannot expect very different behaviour with other fillin times, as has been observed with the biconcave lens.

The variation of the pressure difference is plotted in Fig. 7 as a function of the edge thickness. The change in behaviour point is around $500 \mu \mathrm{m}$. The same kind of representation and

\begin{tabular}{|c|c|c|c|c|c|}
\hline $\begin{array}{c}\text { Minimum } \\
\text { thickness (mm) }\end{array}$ & 0,2 & 0,3 & 0,5 & 0,6 & 0,65 \\
\hline Weld lines & & & & \\
\hline Air Traps & & $*$ & & & \\
\hline
\end{tabular}

Fig. 6. Evolution of the weld lines and air traps for several thickness, using $0.3 \mathrm{~s}$ as fillin time.
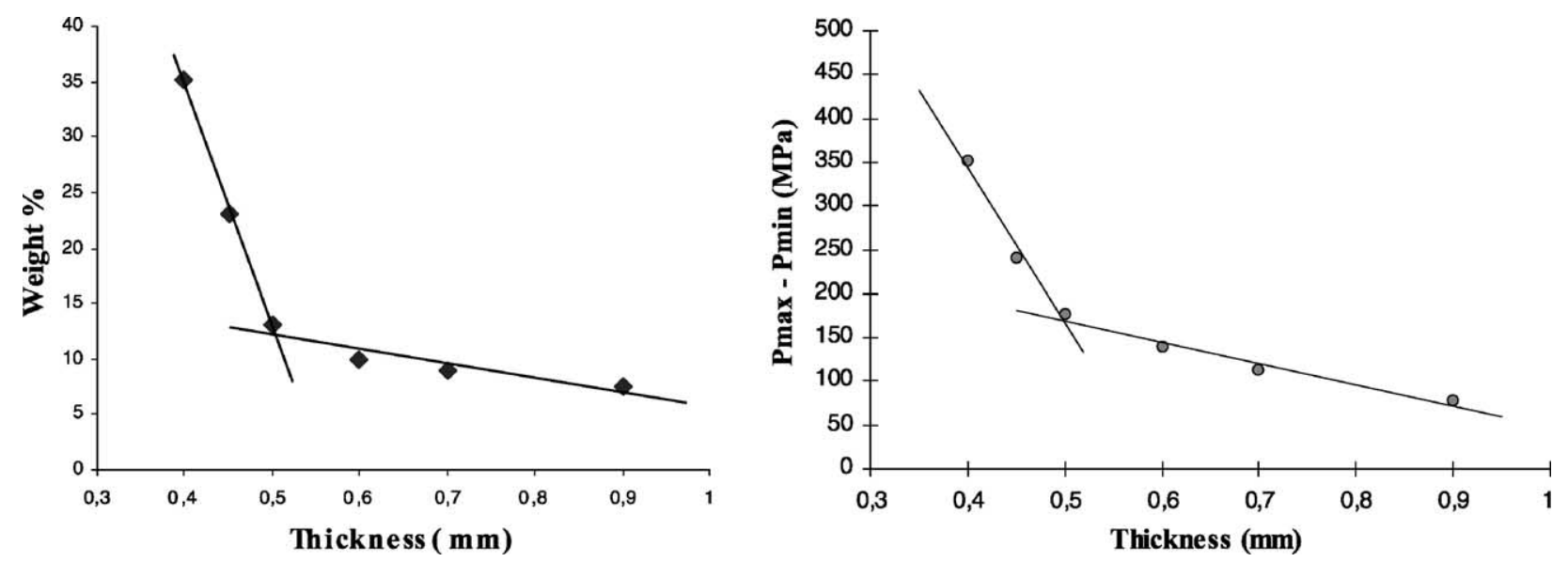

Fig. 7. Pressure differences between the elements with maximum and minimum pressure (right) and percentage of weight (left) using $0.6 \mathrm{~s}$ of fillin time for biconvex lenses, as a function of edge thickness. 


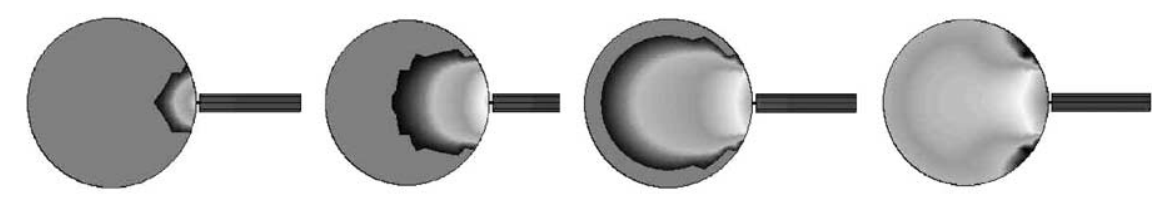

Fig. 8. Melt front advance for biconvex lenses with a central thickness of $300 \mu \mathrm{m}$.

\begin{tabular}{|c|c|c|c|c|c|}
\hline $\begin{array}{c}\text { Minimum } \\
\text { thickness (mm) }\end{array}$ & 0.3 & 0.4 & 0.45 & 0.5 & 0.6 \\
\hline Air Traps & & & & \\
\hline
\end{tabular}

Fig. 9. Evolution of air traps for several thickness using a fillin time of $0.6 \mathrm{~s}$.

the same intersection value are obtained if the percentage of weight and the clamp force are plotted versus the thickness.

Fig. 8 shows the melt-front advance for lenses with a central area thickness of $300 \mu \mathrm{m}$. It is very different from the biconcave lens. Now the thickness restriction is in the edge and the melt plastic mainly $\mathrm{fl} w$ through the central area. The last drawing of this figur allows us to understand how the air trap locations now change to edge areas very close to the runner.

Fig. 9 shows the location of the air traps for different thicknesses. It is very difficul to extract conclusions now, but it is possible to see how the air traps are mainly located in front of the runner if the thickness is higher than $500 \mu \mathrm{m}$.

\section{Conclusions}

CAE tools can not only help design the moulds and optimise the process conditions, they also allow us to estimate some limits in injection moulding processes like the minimum thickness of the thinnest area for which the process gives us a good quality piece.

It is possible to estimate some critical values in the injection process by plotting the value of some variables obtained by simulation versus a geometrical condition as the minimum thickness. The variation of the pressure, weight and clamp force at the end of the fillin process have been observed as the most sensitive parameter for our system (geometry-material-process conditions).

The plots of these variables versus the minimum thickness together with the evolution of the weld/melt lines and the air traps allow us to estimate the critical thickness. From the point of view of the process conditions the critical thickness is $500 \mu \mathrm{m}$ for both kinds of lenses but if other considerations are taken into account the thickness will by higher than $650 \mu \mathrm{m}$ for biconcave lenses and $500 \mu \mathrm{m}$ for biconvex lenses. This is in agreement with what is known by the processors.

\section{Acknowledgements}

The authors wish to thanks M.L. Heijnen for help with the preparation of the manuscript.

\section{References}

[1] L.T. Manzione (Ed.), Applications of Computer Aided Engineering in Injection Molding, Hanser, New York, 1987.

[2] B.H. Lee, B.H. Kim, Polym.-Plast. Technol. Eng. 34 (1995) 793-811.

[3] I. Pandelidis, Q. Zou, Polym. Eng. Sci. 30 (1990) 873-882.

[4] I. Pandelidis, Q. Zou, Polym. Eng. Sci. 30 (1990) 883-892.

[5] H. Lee, B.H. Kim, in: Proceedings of the SPE Annual Technical Conference, ANTEC'95, 1995, pp. 554-560.

[6] W.R. Jong, K.K. Wang, SPE Tech. Pap. 36 (1990) 385-389.

[7] L.S. Turng, H.H. Chiang, J.F. Stevenson, SPE Tech. Pap. 1 (1995) 668-672.

[8] L.W. Seow, Y.C. Lam, J. Mater. Proc. Tech. 72 (1997) 333-341.

[9] M. Gupta, K.K. Wang, SPE Tech. Pap. 2 (1993) 2290-2295.

[10] S.H. Chang, J.R. Hwang, J.L. Doong, J. Grey Syst. 1 (1999) 68-80.

[11] S. Lautenbach, K.X. Wang, H.H. Chiang, W.R. Jonh, in: Proceedings of the SPE Annual Technical Conference, ANTEC'91, 1991, pp. $372-376$.

[12] K.M.B. Jansen, D.L. Van Dijk, E.V. Burgers, Int. Polym. Process. 13 (1) (1998) 99-104.

[13] M. Pazos, Evaluación de variables críticas en el moldeo por inyección de lentes bicócavas y biconvexas, Master's Thesis, Univ. Carlos III de Madrid, Marzo de, 2000.

[14] N. García, Estudio del espesor mínimo para una tarjeta de crédito con microchip, mediante simulación por ordenador, Master's Thesis, Univ. Carlos III de Madrid, Julio, 1999.

[15] E. González, Selección del material más adecuado y optimización del proceso de inyección de una tarjeta de crédito con microchip, mediante simulación con ordenador, Master's Thesis, Univ. Carlos III de Madrid, Marzo de, 2000. 